\title{
Trypargine Blocks the Sodium Channels Only from the Inside of Squid Giant Axon
}

\author{
Issei Seyama, Masuhide Yakehiro, and Terumi Nakajima* \\ Department of Physiology, School of Medicine, Hiroshima University, \\ Hiroshima, 734 Japan \\ *Department of Analytical Chemistry, Faculty of Pharmaceutical Science, \\ University of Tokyo, Tokyo, 113 Japan
}

\begin{abstract}
Summary A new tetrahydro- $\beta$-carboline, trypargine (TRG), specifically suppresses the Na current $\left(I_{\mathrm{Na}}\right)$ when applied to the internal surface of the squid axon membrane without affecting the $\mathrm{K}$ current $\left(I_{\mathrm{K}}\right)$. The binding of TRG to its receptor is potential-dependent and occurs at a site about halfway through the membrane electric field from the outside; the dissociation constant is $11 \mu \mathrm{M}$ at $0 \mathrm{mV}$.
\end{abstract}

Key words: trypargine, Na channel block, guanidinium group

It has been reported that the guanidinium group plays an important role in the suppression of $I_{\mathrm{Na}}$ both for external blocker (KAO and NisHIYAMA, 1965; HILLE, 1975) and for internal blocker (KIRSCH et al., 1980; MoRello et al., 1980). Since TRG, isolated from the African frog Kassina senegalensis (AkizAwa et al., 1982), has a terminal guanidinium group, it was thought worthwhile to test whether TRG could exert an inhibitory effect on the Na channel. Moreover neurochemical investigation has made clear that tetra- $\beta$-carboline which is chemically analogous to TRG is present in the rat arcuate nucleus (SHOEMAKER et al., 1978) or in the rat forebrain (HONECKER and ROMMELSPACHER, 1978). The finding that intraperitoneal administration of tetra- $\beta$-carbolines increased concentration of 5 -HT in mouse and rat brain (McIsAAC et al., 1972) promotes the idea that $\beta$-carboline may serve as an endogenous neuromodulator or neurotransmitter in the 5-HT containing nerve endings (BuCKHOLTZ, 1980). In order to elucidate the mechanism of action of TRG to the nerve membrane, a pharmacological study of TRG was carried out on squid axons isolated from Doryteuthis bleekeli or Sepioteuthis lessoniana. A combined method for internal perfusion and voltage clamp was used in all experiments.

As shown in Fig. 1A (lower left figure) TRG suppressed the peak inward current in such a way that the degree of inhibition was enhanced as the membrane

Received for publication January 7, 1985

瀬山一正, 焼広益秀, 中鴆暉躬 
potential was stepped to more depolarized levels. The steady-state outward current was enhanced at potentials lower than about $+50 \mathrm{mV}$ and suppressed at potentials higher than $+50 \mathrm{mV}$ (Fig. $1 \mathrm{~A}$, see I-V curve).
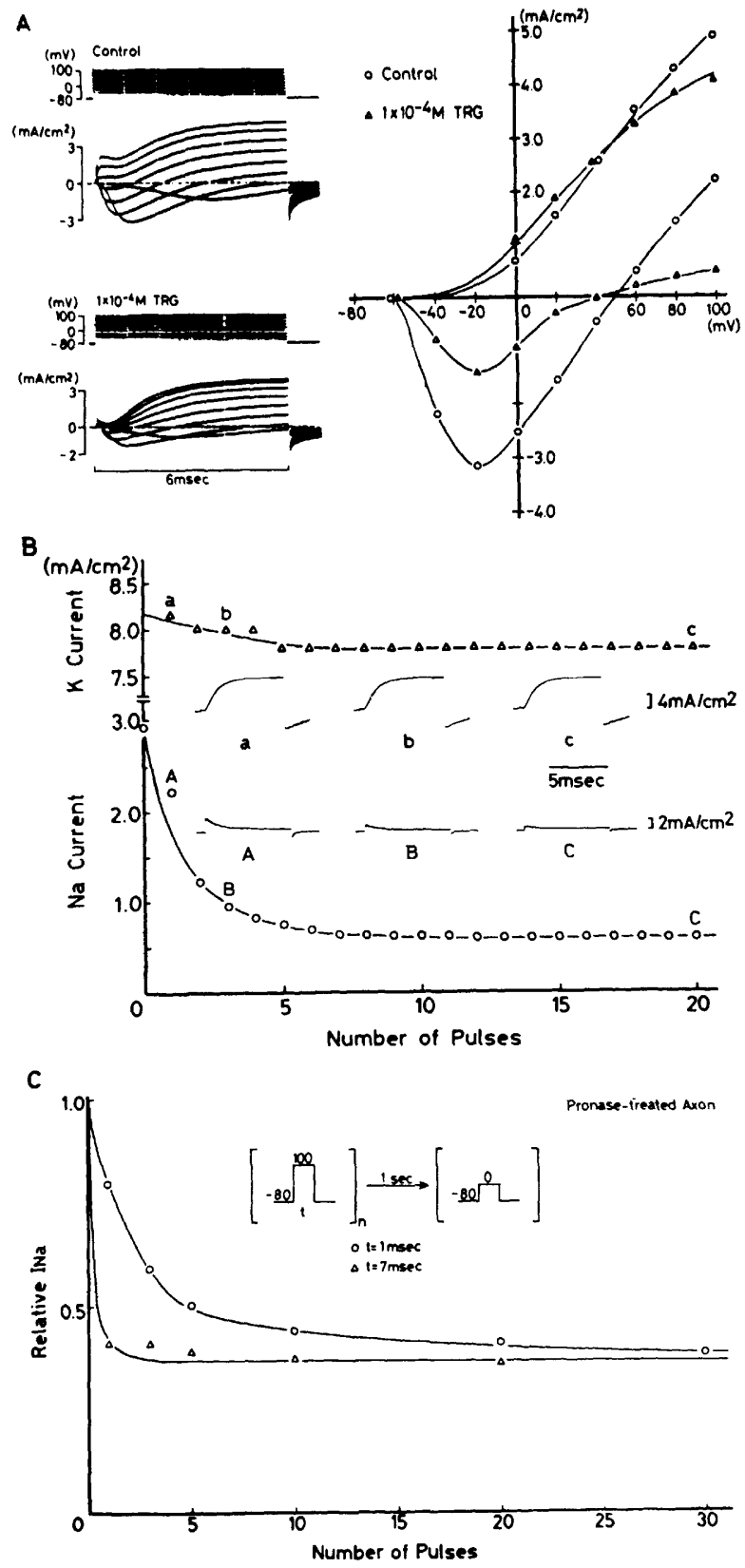

Fig. 1 
This curious behavior of the steady-state current in the presence of TRG strongly suggests that TRG specifically inhibits $I_{\mathrm{Na}}$ without affecting $I_{\mathrm{K}}$. Since the inactivation of $I_{\mathrm{Na}}$ in the perfused axon is incomplete, the total membrane current measured at the end of a $6 \mathrm{msec}$ step depolarization is mainly composed of inward-directed $I_{\mathrm{Na}}$ and outward-directed $I_{\mathrm{K}}$ at potentials lower than $E_{\mathrm{Na}}(54$ $\mathrm{mV}$ ). In contrast, both $I_{\mathrm{Na}}$ and $I_{\mathrm{K}}$ are outward at potentials higher than $E_{\mathrm{Na}}$. If TRG specifically suppressed $I_{\mathrm{Na}}$, the steady-state current would then be composed primarily of outward-going $I_{\mathrm{K}}$. Thus, under the action of TRG, the total steady-state membrane current in response to step depolarizations of less than $+54 \mathrm{mV}$ should be larger than that in control, whereas the steady-state current should be smaller for depolarizations beyond $54 \mathrm{mV}$. This supposition is clearly supported by the data shown in Fig. 1A. To clarify the action of TRG on the individual current systems of the axonal membrane, the effect of TRG on either $I_{\mathrm{Na}}$ or $I_{\mathrm{K}}$ was checked in separate experiments. Figure $1 \mathrm{~B}$ shows that TRG at a concentration of $1 \times 10^{-5} \mathrm{M}$ did not suppress $I_{\mathrm{K}}$ (upper column), but did suppress $I_{\mathrm{Na}}($ lower column) in a frequency dependent manner. When applied externally,

Fig. 1. A. The effect of intracellular application of $1 \times 10^{-4} \mathrm{M}$ TRG on both transient and steady-state currents. The composition of the external solution, i.e., artificial sea water, (ASW) (in mM) is: $\mathrm{NaCl} 449, \mathrm{KCl} 10, \mathrm{CaCl}_{2}$ 50, TRIS 30. Temperature-corrected $\mathrm{pH}$ was adjusted to 8.0. The standard internal solution (SIS) contains: NaF 50, $\mathrm{K}$ glutamate $320, \mathrm{~K}$ phosphate buffer, 15 sucrose 333. $\mathrm{pH}$ was adjusted to 7.3. Temperature was $12^{\circ} \mathrm{C}$. Membrane currents were elicited by step depolarizations from a holding potential of $-8.0 \mathrm{mV}$ in increments of $20 \mathrm{mV}$. The frequency of stimulation was set arbitrarily. The upper left inset figure shows original records for the control, and the lower one, those for $1 \times 10^{-4} \mathrm{M}$ TRG. I-V curve for both transient and steady-state currents is presented to the right.

B. Selective action of TRG on $I_{\mathrm{Na}}$. Upper graph: Lack of effect on $I_{\mathrm{K}}$. $I_{\mathrm{K}}$ was recorded in a medium (ASW/SIS) containing $1 \times 10^{-6} \mathrm{M}$ tetrodotoxin (TTX) externally. Step depolarizations of $180 \mathrm{mV}$ from the holding potential $(-80 \mathrm{mV})$ were applied at a frequency of $1 /$ sec. In the upper graph, internal application of $1 \times 10^{-5} \mathrm{M}$ TRG did not change the amplitude of $I_{\mathrm{K}}$. The slight reduction of $I_{\mathrm{K}}$ with repetitive pulsing is most likely due to $\mathrm{K}^{+}$ion accumulation in the so-called Frankenfaeuser-Hodgkin space. Lower graph: Block of $I_{\mathrm{Na}}$. In order to eliminate $I_{\mathrm{K}}$ and isolate $I_{\mathrm{Na}}, \mathrm{K}$-free ASW was used as the external perfusate and Cs-SIS, as the internal perfusate (composition in mM: NaF, 8.4; NaOH, 41.6; CsF, 41.6; CsOH, 208.4; sucrose, 500; and HEPES, 10). $\mathrm{pH}$ was adjusted to 7.3 by L-glutamic acid. The same pulse sequence was used. The solid line is a single exponential fitted to the data points with a time constant of $1.95 \mathrm{sec}$.

C. The dependency of TRG-induced suppression of $I_{\mathrm{Na}}$ on pulse duration in pronase-treated axon in a medium containing $1 \times 10^{-5} \mathrm{M}$ TRG. A train of depolarizing conditioning pulses of $180 \mathrm{mV}$ having a duration of $1 \mathrm{msec}(O)$ or $7 \mathrm{msec}(\triangle)$ were applied at a frequency of $1 / \mathrm{sec}$. The extent of inhibition of $I_{\mathrm{Na}}$ was estimated by applying a single $80 \mathrm{mV}$ depolarizing test pulse $1 \mathrm{sec}$ after the last conditioning pulse. $I_{\mathrm{Na}}$ at $1 \mathrm{msec}$ from the beginning of test pulse associated with each conditioning pulse was normalized to the value obtained without conditioning pulses. Since recovery from TRG-induced block occurred at the time constant of $18.5 \pm 3.5 \mathrm{sec}$ (mean \pm S.E.) $(n=4)$, the pause between each train of conditioning pulses was set at $2 \mathrm{~min}$. 
TRG at a concentration up to $1 \times 10^{-4} \mathrm{M}$ did not affect any current.

The gating mechanism of $\mathrm{Na}$ channel may regulate the accessibility of the drug to a receptor within the channel; hence, experiments were carried out using pronase-treated axons. In this condition, the availability of open $\mathrm{Na}$ channels can be determined by the length of the depolarizing pulses. When step depolarization with duration of $1 \mathrm{msec}$ was applied at a frequency of $1 / \mathrm{sec}$, the intracellular administration of TRG (at $1 \times 10^{-5} \mathrm{M}$ ) suppressed $I_{\mathrm{Na}}$ in a frequency dependent manner (Fig. 1C). The time course of suppression of $I_{\mathrm{Na}}$ is very similar to that in the h-gate intact axon shown in Fig. 1B. On the other hand, when the duration of step depolarization extended to $7 \mathrm{msec}$ again at a frequency of $1 / \mathrm{sec}$, suppression occurred at the very first stimulation, and subsequent application of the stimulating pulses did not produce further suppression of $I_{\mathrm{Na}}$ (Fig. 1C). The time course of decline of $I_{\mathrm{Na}}$ during the first stimulating pulse followed a single exponential after asymptotic correction (Fig. 2A).

If one assumes that TRG binds to its receptor with a one-to-one stoichiometry when the $\mathrm{Na}$ channel is open, and thereby induces the occlusion of the $\mathrm{Na}$ channel, the process can be represented as: resting channel $\stackrel{\text { H-H}}{\rightleftharpoons}$ open channel $\stackrel{k}{\rightleftharpoons}$ TRG occluded channel, where $\mathrm{H}-\mathrm{H}$ indicates Hodgkin \& Huxley (HoDGKIN and HUXLEY, 1952) kinetics and $k\left(\mathrm{~ms}^{-1}\right)$ is a function of the TRG concentration in the internal solution, namely, $k=b$ [TRG], where $b$ is a constant in liters $\times$ mole $^{-1}$ $\times \mathrm{ms}^{-1}$ (ARMstrong, 1969). The time constant from the falling phase of $I_{\mathrm{Na}}$ (in pronase-treated axons) is related to $k$ and $l$ by

$$
\tau=\frac{1}{k+l}
$$

The ratio of steady-state $I_{\mathrm{Na}}$ in the presence of TRG to that in the control is

$$
\tau l=\frac{l}{k+l}
$$

The rate constants were calculated from these two equations and plotted against the membrane potential on a semilogarithmic graph (Fig. 2 B-1 and B-2).

The dependency of the dissociation constant, $K_{\mathrm{D}}(E)$, for TRG on the membrane potential was elucidated by the following procedure: (1) The degree of suppression of steady-state $I_{\mathrm{Na}}$ in response to a depolarizing pulse was calculated from ( $I_{\mathrm{Na}, \mathrm{contro}}$ $\left.-I_{\mathrm{Na}, \mathrm{TRG}}\right) / I_{\mathrm{Na}, \text { control }}$, and plotted against the TRG concentrations (i.e., $10^{-6} \mathrm{M}$, $10^{-5} \mathrm{M}, 3 \times 10^{-5} \mathrm{M}$ and $\left.10^{-4} \mathrm{M}\right)$. (2) The relative suppression of $I_{\mathrm{Na}}$ is $1 /\left(1+K_{\mathrm{D}}(E) /\right.$ [TRG]), (assuming that the drug binds to a receptor with one-to-one stoichiometry), where $K_{\mathrm{D}}(E)$ is the apparent dissociation constant, and [TRG], TRG concentration in M. (3) $K_{\mathrm{D}}(E)$ was determined as the concentration at which half suppression of steady-state $I_{\mathrm{Na}}$ occurred. According to the model proposed by WoODHULL (1973), drug access to the receptor is via a hydrophilic pathway and the drug is bound to a receptor which experiences a fraction, $\delta$, of the membrane field. The relationship between $K_{\mathrm{D}}(E)$ and membrane potential is expressed as $K_{\mathrm{D}}(E)=K_{\mathrm{D}} \exp [(\delta-1)$ 
A-1

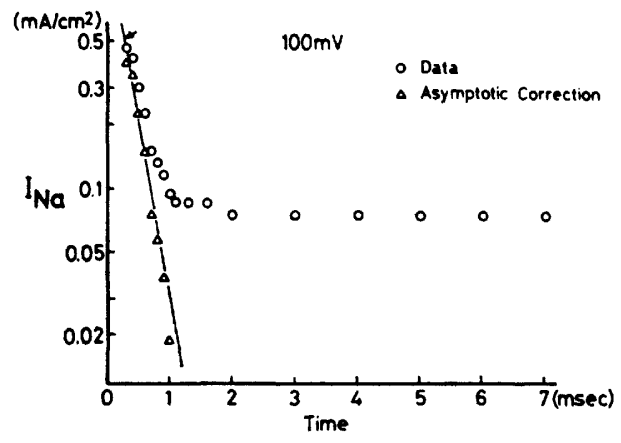

B-1

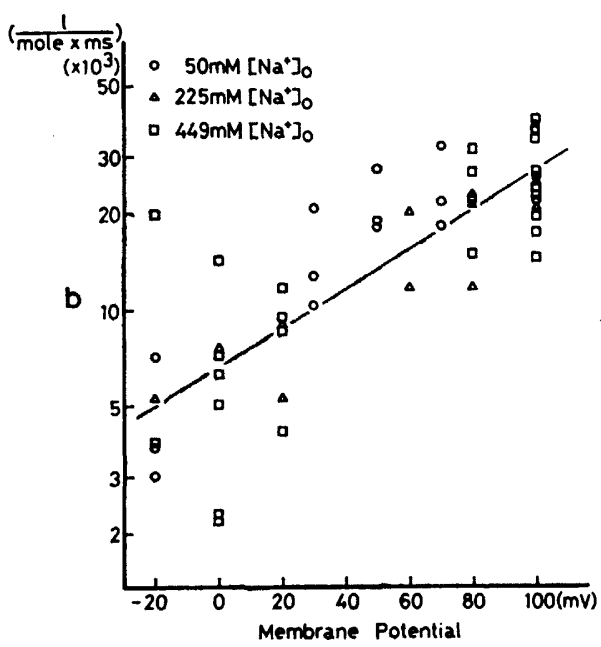

A-2

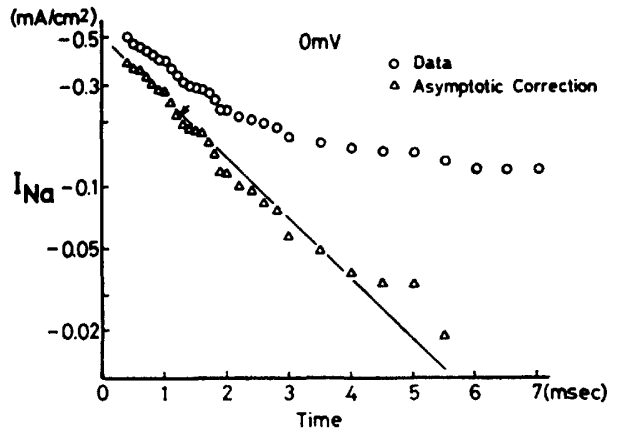

B 2

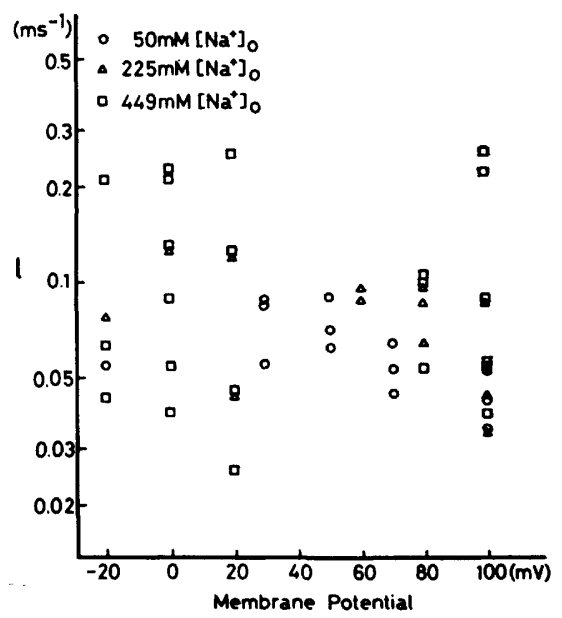

Fig. 2. A. Time course of decay of sodium current due to the action of TRG in pronase-treated axon. The experiments were done in K-free ASW/Cs-SIS. A-1 and A-2: Semilogarithmic plot of the falling phase of $I_{\mathrm{Na}}$ in the presence of TRG $\left(1 \times 10^{-4} \mathrm{M}\right)$ at two potentials. A-1 indicates the data for $I_{\mathrm{Na}}$ in response to a depolarizing pulse of $180 \mathrm{mV}$ from $-80 \mathrm{mV}$ and A-2, that in response to a pulse of $80 \mathrm{mV}$. Arrows indicate time constants of decay of $I_{\mathrm{Na}}$; these were calculated to be $0.25 \mathrm{msec}$ at $+100 \mathrm{mV}(\mathrm{A}-1)$ and $1.28 \mathrm{msec}$ at $0 \mathrm{mV}$ (A-2). The membrane current and potential recorded on $35 \mathrm{~mm}$ film were projected on graph paper and measurements were made manually.

B. Relationship between the rate constants $\mathrm{b}(\mathrm{B}-1)$ and $l(\mathrm{~B}-2)$ and the membrane potential for TRG $\left(1 \times 10^{-4} \mathrm{M}, 1 \times 10^{-5} \mathrm{M}\right)$. The wide range of data for $I_{\mathrm{Na}}$ was covered by preparing the solutions having various concentrations of sodium ion, where $\mathrm{Na}$ was replaced with tetramethylammonium. $\bigcirc ; 50 \mathrm{~mm}\left[\mathrm{Na}^{+}\right]_{0}, \triangle ; 225 \mathrm{~mm}\left[\mathrm{Na}^{+}\right]_{0}, \square ; 449 \mathrm{~mm}$ $\left[\mathrm{Na}^{+}\right]_{0}$. The solid line for B-1 was fitted by $b=2.15 \times 10^{3} \times \exp (0.00142 \times V)$, where $V(\mathrm{mV})$ is the size of the step made from a holding potential of $-80 \mathrm{mV}$. The backward rate constant, $l$, was independent of the membrane potential during stimulating pulses. 
$z F E / R T]$, where $K_{\mathrm{D}}(11 \mu \mathrm{M})$ is the dissociation constant at zero membrane potential, $\delta$, the fraction of membrane potential acting on binding site, $z$, the valency of TRG, and $E$, the membrane potential, and $F, R$ and $T$ have their usual meanings. Because the $p K_{\mathrm{a}}$ for TRG is more than 12, almost all of TRG should be positively charged in the internal perfusate. When the gate of $\mathrm{Na}$ channel is open, TRG binds to a site calculated to be about halfway $(\delta=0.46)$ through the membrane field from the outside.

Since an increase in the available 5-HT (e.g., as caused by increased synthesis or decreased reuptake) leads to a depression of firing rate in 5-HT containing cells (AGHAJANIAN and WANG, 1978), it has been proposed that the inhibitory action of tetrahydro- $\beta$-carboline to 5 -HT containing cell may be due to the inhibition of MAO activity and the modification of transmitter release (BUCKHOLTZ, 1980). In taking account of the inhibitory action of TRG on the $\mathrm{Na}$ channel, another possible action of tetrahydro- $\beta$-carboline for the regulation of transmitter release of 5 -HT containing cells is that tetrahydro- $\beta$-carboline may act as endogeneous neuromodulator through the inhibition of $\mathrm{Na}$ channel which in turn reduces the degree of opening of $\mathrm{Ca}$ channel and modulates the transmitter release.

The authors greatly appreciate the help of Professor A. Watanabe, National Institute for Physiological Science, Okazaki, Japan, and Professor A. Inaba, Marine Biological Station, Hiroshima University, Mukaijima, Onomichi, Japan, for constant encouragement and supplying squid. Thanks are also due to Dr. S. Vogel (Northwestern University, USA) for his help in correcting the English manuscript. This work was partly supported by a grant from the Ministry of Health and Welfare of Japan.

\section{REFERENCES}

Aghajanian, G. K. and WANG, R. Y. (1978) Physiology and pharmacology of central serotonergic neurons. In: Psychopharmacology: A generation of progress, ed. by Lipton, M. A., DiMascio, A. and Killam, K. F. Raven Press, New York, pp. 171-183.

akizawa, T., Yamazaki, K., Yasuhara, T., Nakajima, T., Roseghini, M., Erspamer, G. F., and ERSPAMER, V. (1982) Trypargine, a new tetrahydro- $\beta$-carboline of animal origin: Isolation and chemical characterization from the skin of the African rhacophorid frog, Kassina senegalensis. Biomedical Res., 3: 232-234.

ARMSTRONG, C. M. (1969) Inactivation of the potassium conductance and related phenomena caused by quaternary ammonium ion injection in squid axons. J. Gen. Physiol., 54: 553575.

Buckholtz, N. S. (1980) Neurobiology of tetrahydro- $\beta$-carbolines. Life Science, 27: 893-903.

Hille, B. (1975) The receptor for tetrodotoxin and saxitoxin. A structural hypothesis. Biophys. $J ., 15: 615-619$.

Hodgkin, A. L. and Huxley, A. F. (1952) A quantitative description of membrane current and its application to conduction and excitation in nerve. J. Physiol. (Lond.), 117: 500-544.

HONECKER, H. and ROMMELSPACHER, H. (1978) Tetrahydronorharmane (tetrahydro- $\beta$-carboline), a physiologically occurring compound of indole metabolism. Naunyn-Schmiedeberg's Arch. Pharmacol., 305: 135-141.

KAO, C. Y. and NishIYAMA, A. (1965) Actions of saxitoxin on peripheral neuromuscular systems. J. Physiol. (Lond.), 180: 50-66. 
KIrSCH, G. E., YeH, J. Z., Farley, J. M., and Narahashi, T. (1980) Interaction of $n$-alkylguanidines with the sodium channels of squid axon membrane. J. Gen. Physiol., 76: 315335 .

McIsaAC, W. M., TaYlor, D., Walker, K. E., and Ho, B. T. (1972) 6-Methoxy-1,2,3,4tetrahydro- $\beta$-carboline-a serotonin elevator. J. Neurochem., 19: 1203-1206.

Morello, R., Begenisich, T., Trzos, W., and ReED, J. K. (1980) Interaction of nonylguanidine with the sodium channel. Biophys. J., 31 : 435-440.

Shoemaker, D.W., Cummins, J.T., and Bidder, T.G. (1978) $\beta$-carbolines in rat arcuate nucleus. Neuroscience, 3: 233-239.

Woodhull, A. M. (1973) Ionic blockage of sodium channels in nerve. J. Gen. Physiol., 61: $687-708$. 